This is a pre-print version of an article that has been published in the International Journal of Heritage Studies. The published version can be downloaded from:

http://www.tandfonline.com/doi/abs/10.1080/13527258.2012.738334

Please cite this article as:

Van der Hoeven, A. (2014). Remembering the popular music of the 1990s: dance music and the cultural meanings of decade-based nostalgia. International Journal of Heritage Studies, 20(3), 316-330.

\title{
Remembering the popular music of the 1990s: dance music and the cultural meanings of decade-based nostalgia
}

\section{Arno van der Hoeven}

Following the popularisation of dance music in the 1990s, and the consolidation of disc jockeys (DJs) as global stars, this article examines the attachment of music audiences to this decade by examining the popular flashback dance parties held in the Netherlands. By drawing on theories of cultural heritage, memory and nostalgia, this article explores 1990s-themed parties as spaces where music audiences construct cultural identities and engage with their musical memories. Based on in-depth interviews with audience members, DJs and organisers of dance events, this study examines the meaning of cultural memories and the manner in which nostalgia arises in specific sociocultural settings. The findings indicate two ways in which cultural memories take shape. At early-parties, DJs and audiences return to the roots of specific genres and try to preserve these sounds. Decade-parties offer an experience of reminiscence by loosely signifying the decade and its diverse mix of music styles and fashions.

Keywords: popular music; dance music; cultural heritage; cultural memory; nostalgia

\section{Introduction}

House the 90 s is the party that takes you back to the atmosphere of the 1990s with all of the big house hits from the period in one of the best venues out there (Noa). Were you at Thunderdome in '96, going crazy to house classics or singing along to Life's like a dance and Luv you more? If so, then this is the party for you. (House the 90s, Leeuwarden) 1

This quote is taken from a website promoting one of the many Dutch parties that focuses on music from the 1990s in particular. At these events, disc jockeys (DJs) mix songs from the period for those who grew up in or are otherwise interested in this decade. As Kotarba (2002, p. 400) notes, the segmentation of music history in discrete periods like the 'nineties' is often used by the cultural industries 'as a simple and convenient framework for portraying history in a nostalgic framework'. In this article, I consider how popular music memories of this decade are constructed at 1990s-orientated dance parties. Bennett (2009) showed that rock music has become part of cultural heritage discourses; the memories of music scenes and traditions are preserved as cultural heritage because they give shape to collective identities. Against this backdrop, several researchers have examined both the attachment of music audiences to the sounds of their youth (Holbrook and Schindler 1989, Bennett 2006, Mulder et al. 2010) and the manner in which popular music is positioned as cultural heritage (Kong 1999, Burgoyne 2003, Schmutz 2005, van Dijck 2006, Bennett 2009).

I aim to contribute to these debates by exploring how dance music becomes part of narratives of cultural memory and examining the ways in which these memories are valorised by DJs and party organisers. Outside the domain of historical investigation and traditional institutions like museums (Kong 1999, 
Burgoyne 2003) and cultural education (Bevers 2005), the cultural industries contribute to representations of popular music history by 'marketing memory' with products like reissues, flashback

parties and documentaries (Baer 2001). Since cultural industries increasingly function as disseminators of narratives of cultural memory, it is timely to study how they provide spaces in which links to the past can be retained. Moreover, in the existing literature, there has been very little discussion of the ways audiences consume and give meaning to popular music heritage.

These considerations lead to the following research question: how are cultural memories of the popular music of the 1990s negotiated at dance parties focused on that period in Dutch popular music history?2 Following on from the success of DJs and dance music in the 1990s, this article explores how local popular music heritages are constructed at flashback dance parties. On the basis of qualitative interviews with both audience members and cultural industry workers, I examine how audiences' memories interact with the practices of DJs and the organisers of these dance events. The article focuses on dance-parties, because such events are an opportunity for audiences to get together and celebrate a collective identity (Bennett 2006). Moreover, they provide a platform for the reenactment of memories (Wu 2010). In the next section of the article, I will discuss how other researchers have conceptualised this engagement of audiences and cultural industries with music of the past.

\section{Theorising popular music of the past 2.1. Popular music as cultural heritage}

The study of popular music has always been closely associated with the study of youth (Hesmondhalgh 2005 , Bennett 2006, 2008). This is unsurprising given the important role that popular music plays in young people's lives. Music is particularly powerful in aiding identity construction during teenagers' formative years:

It facilitates the choice of an identity, as well as its expression, and by enabling experimentation it serves as an imaginative platform on which to perform, construct and negotiate one's own identity, and situate oneself in the social world. (Mulder et al. 2010, p. 69)

Since every generation grows up with different styles of music, popular music makes it possible to identify a group of people as being part of a particular decade. For instance, the beat music of the 1960s was intertwined with the youth culture of the post-war generation and helped these young people to claim their own identity and rebel against their parents and the authorities. As Bennett thus argues, 'rock is now embedded firmly in the cultural memory of an ageing baby-boomer generation [...] as a key element in their collective cultural awareness and a major contributor to their generational identity' (2009, p. 478). For this reason, several authors examine how the attachment to popular music develops when people get older (Holbrook and Schindler 1989, Bennett 2006, Mulder et al. 2010). Given the fact that popular music is so important in the lives of young people, researchers are interested in how these audiences engage with their music memories during adulthood. This means that the attention of authors starts to shift towards older music audiences and the ways in which cultural industries shape popular music memories.

Bennett (2009) contributes to these debates by showing how various actors (re)position rock music as part of narratives of cultural heritage. Print and visual media have retrospectively consecrated the work of artists in order to establish their historical importance and give them a place in the rock canon (Schmutz 2005). Likewise, museums and other institutions shape our understanding of popular music heritage by putting it on display and thus endowing particular events with historical relevance. Here, 'vernacular memories', which are the first-hand experiences of particular communities, coalesce with official memories offering authoritative narratives of popular music history (Burgoyne 2003). Moreover, Bennett shows how fans engage in discussions of what are defining moments in rock history. As do-it-yourself preservationists, they make use of digital tools such as weblogs to draw attention to alternative understandings of popular 
music's past. Finally, commercial products give form to renderings of popular music as heritage. The music industries and the aforementioned print and visual media rummage through popular music history to produce commercial memories that preserve cultural heritages.

Since affluent adult consumers are an interesting group to target with music from their youth (Holbrook and Schindler 1989, Bennett 2009), older music fans have become an important market for the cultural industries. Moreover, people who do not have first-hand experience of a particular musical period are also part of the target population. For young people, these memory products are a way to 'catch up with' popular music history. Bennett (2008) describes this process, through which they construct their own understanding of a decade of which they have no living memory, as 'received nostalgia'. So, both younger and older audiences are interested in products like reissues, performances of 'classic' albums and the 1990s parties that are the subject of this study. Audiences buy these items in order to explore popular music history and use them as cultural tools to relate their autobiographical experiences to public accounts of the past (Wertsch 2002, van Dijck 2004). Thus, cultural industries offer cultural narratives with which audiences can identify. In relation to this, Burgoyne (2003, p. 211) contends that 'perhaps even more influential than official memory in the present day, commercial culture engages the discourses of memory by invoking commercial products and representations as an aspect of national heritage'.

This recycling of the past by the cultural industries is often conceptualised as nostalgia (Hayes 2006, Bennett 2008). Reynolds (2011), for instance, argues that nostalgia has become such a ubiquitous feature of popular culture that 'we live in a pop age gone loco for retro and crazy for commemoration' (p. ix). Reynolds blames the music industry for being so preoccupied with old styles that this hampers creative innovation. This is in line with the argument of Pickering and Keightley (2006), namely that music is more likely to induce feelings of nostalgia than other forms of media because 'it can carry a powerful affective or sensuous charge' (p. 935). In the next section of this article, I will discuss existing theories of nostalgia as cultural memory in order to situate my own research.

\subsection{Popular music and nostalgia}

In Yearning for Yesterday, Davis (1979) defines nostalgia as 'a positively toned evocation of a lived past in the context of some negative feeling toward present or impending circumstances' (p. 18). This definition highlights that nostalgia is related to both the past and the present. People hold on to it, in order to retain links to the past. On a personal level, nostalgia is a tool through which we can experience continuity in our lives (Sedikides et al. 2008). Individual identities are rooted in the past and nostalgia makes an ongoing engagement with bygone days possible. For this reason, listening to popular music is closely related to autobiographic remembering (DeNora 1999, Janata et al. 2007). Moreover, by means of selection, nostalgia helps us to identify particular generations. Nostalgia selects 'those scenes, events, personalities, attitudes, and practices from the past that make an identifiable generation of what would otherwise remain a featureless demographic cohort' (Davis 1979, p. 111). In this selection process, the happy memories often prevail. In this conception, nostalgia thus functions as a rose-tinted representation of the past that enables us to forget a less attractive present or future. Feelings of nostalgia are thus bound up with transitions on a societal and individual level. For this reason, nostalgia is often understood in connection to modernity and accompanying feelings of loss in the face of a society that continuously discards the past for the sake of progress (Grainge 2000, Pickering and Keightley 2006).

As a result of these putative negative contexts that give rise to nostalgic feelings and a manufactured understanding of the past, nostalgia is commonly associated with negative terms suggesting that it is an impediment to progress or reactionary (Pickering and Keightley 2006), or that it leads to creative bankruptcy or postmodern amnesia (Grainge 2000, Baer 2001). The latter two negative connotations, in particular, become apparent in Reynolds's (2011) book on the current state of the music industry. Reynolds (2011, p. xiv) asks provocatively, 'Is nostalgia stopping our culture's ability to surge forward, or are we nostalgic precisely because our culture has stopped moving forward and so we inevitably look back to more momentous and dynamic times?' This frames feelings of nostalgia not as an adaptation to the feelings of loss we have experienced, but as an indication of cultural amnesia (Grainge 2000). This interpretation 
suggests that our culture trivialises history by randomly recycling bits and pieces of the past. Jameson $(1985,1991)$ claims that this split between signifier and what is signified leads us to a state of depthless presents. The unceasing revivals and recycling of old fads and fashions make it hard to distinguish between then and now. Ironically then, the preoccupation with the past implies a waning of historicity because it understands the past solely in the context of the present (Jameson 1985). Moreover, when following this line of thought, nostalgic understandings of the past are skewed because they only focus on its positive aspects. Postmodern accounts of memory highlight how cultural recycling through pastiche and stereotyping compromises the historical accuracy of popular cultural forms like television, movies and music (Hoskins 2001, Pickering and Keightley 2006). These are sentiments that are echoed in Reynolds' contention (2011) that nostalgia hampers musical creativity because of its obsession with the past.

In response to these negative understandings of nostalgia, Pickering and Keightley (2006) contend that the meaning-making processes of audiences should also be considered to see how they actually engage with the past. These researchers shift the focus from the nostalgic content to the meanings that audiences attach to memory products. In a similar vein, Grainge (2000) argues that nostalgia should not be reduced to mere categories of cultural longing or postmodern forgetting, as Davis (1979) and Jameson (1991) do, respectively. Instead, we have to look at how traces of the past prevail in our culture and how these are used by audiences and cultural industries to construct cultural narratives. Pickering and Keightley (2006) thus argue that researchers should move beyond conceptions of nostalgia in which audiences are viewed as passively absorbing nostalgic content. In other words, media and cultural industries do not disseminate 'nostalgic narratives' that remain unchallenged by their audiences:

An investigation of the ways in which audiences may actively engage in the cultural making of meaning is not considered. We need to investigate the interaction between different sites of meaning-making if we are to move nostalgia away from a nebulous characterization of a particular orientation to the past, and engage instead with the distinct and specific ways in which contemporary interaction with the past is enacted. (Pickering and Keightley 2006, p. 929)

This is in accordance with approaches to heritage that emphasise the active processes of remembering that occur at heritage sites (Smith 2006). Bagnall (2003, p. 88) contends that heritage is not uncritically consumed by audiences, but that heritage sites 'allow visitors to connect to personal and cultural memories and biographies, and to practice and perform a form of reminiscence'. This frames heritage as a physical and emotional experience from which visitors derive personal meanings.

However, while the evoked feelings and memories might relate to individual biographies, they nevertheless arise in sociocultural settings. According to van Dijck (2006, p. 358), 'remembrance is always embedded, meaning that the larger social contexts in which individuals live stimulate memories of the past through frames generated in the present'. Since music fosters a sense of belonging, people form communities with shared heritages or a common past which they nostalgically cherish. At the same time, individuals have agency to appropriate this heritage in a personal way. As Bagnall (2003, p. 96) argues that: 'This reflects the tension in contemporary western society between reflexivity of behavior and the degree to which such behavior is socially embedded, located in social relations and routines'. Individuals do not passively absorb accounts of the past, but always engage with their personal biographies in relation to existing cultural narratives. People draw on cultural tools such as museums, heritage sites and documentaries, which mediate their experiences of the past (Wertsch 2002, Smith 2006). At the same time, these tools are used to exchange memories and constitute collective identities (van Dijck 2006). This leads me to investigate the processes of remembering at 1990s-orientated dance parties. A study of the content of autobiographical musical memories shows that a majority of these recollections are related to dancing and the social contexts in which people enjoy listening to music (Janata et al. 2007). I would thus suggest that the dance floor is also a place where people go to collectively remember the music of their youth. Bennett (2009) demonstrated how live reproductions of classic rock albums contribute to the position of popular music as cultural heritage. I will extend this argument to the dance floor to examine how it functions as a stage for the collective reenactment of the past (Wu 2010). To be clear, I will not study these parties solely in terms of nostalgia; a broader theoretical framework has been utilised because there are 
different perspectives on the past (Lowenthal 1989). The commodification of popular music memories by the cultural industries makes it difficult to demarcate nostalgia and heritage as two discrete phenomena. As Atkinson (2008, p. 388) argues in his study of new articulations of heritage:

This more encompassing approach to memory also draws other forms of remembering within the academic purview. While earlier scholars might shun any mention of emotive phenomena like nostalgia, it is today assessed as a significant cultural phenomenon that exposes the plural and overlapping histories of places.

The concepts of nostalgia and heritage are thus related and need to be studied on this basis.

\section{Data and method}

In order to examine how the cultural industries feed into the cultural memories of the 1990s, I conducted interviews with party organisers, DJs and audience members, employing a theoretical sampling strategy to explore the variety of meanings that these dance parties have for their visitors (Corbin and Strauss 1990). This produced a sample consisting of interviewees aged 21-43 and, in case of the audience members, people who visit different kinds of parties. Some of the interviewees particularly like chart music, while others focus more on non-mainstream genres (i.e. 'underground styles'). The respondents, who were approached through Facebook and a virtual community of the dance scene, also represent various degrees of involvement with popular music and have different educational backgrounds. I conducted 17 semistructured in-depth interviews lasting between $30 \mathrm{~min}$ and an hour each. I spoke to three respondents by telephone and did two double interviews. All of the other interviews were face to face with one person. The sample consists of 14 male and 5 female respondents. The names of the respondents have been changed to preserve their anonymity. I transcribed and coded all of the interviews using ATLAS.ti. This enabled me to compare the content and find patterns in the material. Following on from this analysis, I made an ideal-typical distinction between two ways in which memories of popular music from the 1990s are shaped. I will present this categorisation of early-parties and decade-parties after first introducing the heritage of dance music in the Netherlands.

\section{Background to the study: the heritage of dance music}

To understand dance music's position as cultural heritage, I will briefly consider its legacy in the Netherlands. The history of dance music stretches back to the 1970s in terms of the meaning of dancing in a disco. During the early to mid-1980s, DJs in Chicago adapted disco by blending European electronic music and soul to the genre currently known as house music (Rietveld 2011). Nowadays, the term clubbing is used to describe the activity of dancing to a wide array of dance genres and sub-genres like acid house, drum-n-bass, minimal techno, gabber, techno and rave (McLeod 2001). These labels mark differences between genres and are illustrative

of the current fragmentary nature of dance music. As Bennett (1999, 2001, p. 125) notes:

[...] the splitting and resplitting of dance music genres has ensured that those who once mixed in the common space of the dance floor are now able to find musics and clubs that cater more specifically for particular 'types' of clubber.

This has consequences for the dance crowd's feelings of 'togetherness':

[E]xpressions of 'collective' identity articulated through dance music are largely confined to the temporal setting and atmosphere of the club, the club crowd consisting of individuals whose socio-ethnic origins are often mixed and whose paths rarely cross outside the club setting. (Bennett 2001, p. 127)

If the crowds who follow dance music are indeed so fleeting and unstable, whose heritage are we talking about here? Graham and Howard (2008) contend that heritage presumes a group of people who exclude others because they do not share the values and beliefs of the in-group. As I will explain below, certain dance communities have a strong sense of collective identity and distinguish themselves from outsiders based on their musical taste (Thornton 1995). Moreover, although dance music crowds are fragmented, memories of local dance cultures are increasingly preserved because of their cultural contributions and relevance to a generation that grew up with these styles. Using Harvey's (2008, p. 33) terminology, these 
are the 'small heritages' that will '[perhaps] form the basis of the material, the thoughts, practices and plans that we pass on to the next generation'.

From the 1980s onwards, house travelled over the globe, leading to house scenes and local adaptations by DJs in various European cities. These contributions to the global development of house are now cherished as local heritage and documented in books, exhibitions and documentaries. For instance, in 2001, the Amsterdam Historical Museum gave the career of local DJ Eddy de Clercq a prominent place in its exhibition on 100 years of dancing in the city.

A pivotal Dutch influence on the development of house is the so-called hardcore (gabberhouse) music. Disaffected by the media attention paid to the house scene in Amsterdam, DJs from Rotterdam created a harder house style that 'illustrates the age-old rivalry between the artistic, extravagant Amsterdammers and the plain, hard-working Rotterdammers' (Verhagen et al. 2000, p. 149). Reynolds (1999, p. 283) describes the nihilistic pounding of gabberhouse as 'an ultrafast superaggressive form of hardcore techno developed by the Dutch in the early 1990s that has since spread throughout the global rave underground'. This youth culture of the gabbers, as they were called, had a clearly distinguishable style, with tracksuits by the brand Australian, Nike Air Max trainers and, usually, having completely shaved heads.3 Gabberhouse became popular with the general public when the more commercial, radio-friendly happy hardcore hit the charts (Reynolds 1999). At that point, media parodied the remarkable style of the gabbers, and children's songs were eagerly reworked into happy hardcore tracks by companies looking to make easy money. Because of this mainstream appropriation, the scene collapsed and 'went underground' again (Verhagen et al. 2000). In the remainder of this article, I will explore how the current 1990s parties relate to these musical developments.

\section{Research findings}

\subsection{Ways of remembering: early-parties and decade-parties}

Which music do I like? Particularly early hardcore, early rave and happy hardcore. Though the real happy hardcore of the 1990s, not the commercial happy hardcore.

I: The real happy hardcore?

Yes, not the commercial hits that were in the charts at the time $\ldots$ you know, but the old happy hardcore CDs ... with the music that isn't known to a mainstream audience. (Mathieu, 34)

The quote set out above illustrates that fans of hardcore still take great pains to distance themselves from the commercialisation of the genuine hardcore sound. By using the term 'mainstream', Mathieu distinguishes himself from people who do not possess this subcultural knowledge of early happy hardcore styles (Thornton 1995). This perceived opposition between the 'mainstream' and the 'early sounds' is still notable in the way that parties now engage with the musical heritage of the 1990s. Table 1 shows an idealtypical distinction between 'early-parties' and 'decade-parties'. 4 The early-parties go back to the roots of house music and focus on periods that preceded the mainstream appropriation of particular sub-genres. Here, the music is celebrated as having an 'authentic' underground style that retains its relevance outside the domain of mainstream attention. The attendees at the early-parties are still committed to the gabber identity and, as I will explain below, emphasise the endurance of this collective identity. Following Boym's (2001) distinction of two kinds of nostalgia, the early-parties can be seen as restorative nostalgia and the decade parties as reflective nostalgia. As Boym (2001, p. 41) argues, 'The first category of nostalgics do not think of themselves as nostalgic; they believe that their project is about truth'. At the early-parties, the DJs try to restore the 'authentic' sound of a period, before allegedly disruptive external influences had an impact on the development of particular house genres. Here 'nostalgia functions as a form of romance in which musical memory idealizes the past, excavating and anchoring perfect zero moments, whilst forgetting the incidents, the messy mistakes, the experiments, the accidents' (Rietveld 2011, p. 17). 


\begin{tabular}{|l|l|l|}
\hline Music & $\begin{array}{l}\text { 'Underground': Early rave, } \\
\text { early hardcore }\end{array}$ & $\begin{array}{l}\text { 'Mainstream': music from the } \\
\text { charts }\end{array}$ \\
\hline $\begin{array}{l}\text { DJ-style (Reynolds } \\
\text { 1999) }\end{array}$ & $\begin{array}{l}\text { DJ-Auteur: re-creative artist, } \\
\text { actively producing new work }\end{array}$ & $\begin{array}{l}\text { Passively playing and mixing } \\
\text { records of other artists }\end{array}$ \\
\hline $\begin{array}{l}\text { Level of subcultural } \\
\text { identification (Bennett } \\
\text { 1999, Muggleton 2000, } \\
\text { p. 52) }\end{array}$ & $\begin{array}{l}\text { Modern: strong collective } \\
\text { identity, high degree of } \\
\text { commitment, stylistic } \\
\text { homogeneity }\end{array}$ & $\begin{array}{l}\text { Postmodern: temporary } \\
\text { identifications, stylistic } \\
\text { heterogeneity, post- } \\
\text { subcultural }\end{array}$ \\
\hline $\begin{array}{l}\text { Type of nostalgia } \\
\text { (Boym 2001) }\end{array}$ & Restorative nostalgia & Reflective nostalgia \\
\hline
\end{tabular}

Table 1. Ideal-typical distinction between 'early-parties' and 'decade-parties'

In contrast, the reflective nostalgia of the decade-parties does not pretend to offer accurate, untainted musical memories. During these evenings, references to the 1990s are made in a playful and humourous way, ironically reflecting on the passing of different fashions. These decade-parties offer a blend of chart hits, with the only rule of thumb being that the music should be danceable and recognisable. This approach to the decade is so popular that party organisers lavishly copy this format for events with names like 90s now, Remember 90s and Best of 90s. A typical evening consists of styles ranging from hip hop and boy bands to rock. Here, one is also likely to hear the commercial happy hardcore tracks so despised by the hardcore connoisseurs at the early-parties. From the interviews, it becomes clear that this is a reason for the 'genuine' house fans to avoid these events. Typically, at the decadeparties, the 1990s are invoked in a stereotypical way by signifying the fads and fashions of that period. For instance, these parties often mock the appearance of gabbers. The rapid turnover of popular styles is reflected in the transient experience of these evenings. In some cases, a video jockey will be present, who blends recognizable excerpts of commercials, music videos and films. Together, these elements give party-goers the feeling of a 1990s experience. In line with the variation of musical styles, my own observations suggest that the decadeparties attract a more diverse crowd than the early-parties when it comes to socio-economic backgrounds and lifestyles. Likewise, the strong sense of collective identity of the early-parties is missing here. Since these events are not tied to a particular style, they are more accessible.

What the two types of party have in common is the central role of the DJ, although they use different kinds. Reynolds (1999) makes a distinction between DJs who 'just' play records produced by others and the DJ-auteur who creates new records by remixing existing music. On the one hand, the decade-parties are often hosted by a DJ who, as a living golden-oldie jukebox, seamlessly blends the songs of various artists into one long mix. At the early-parties, however, the DJ-auteurs are celebrated as pioneers of particular styles. While the independent DJ-culture initially developed outside the scope of the major record labels (Hitters and van de Kamp 2010), DJs have now become global stars and are regularly conferred with the critical acclaim previously reserved for rock artists (Bennett 2001). By using a remix aesthetic, taking bits and pieces (i.e. samples) from both older and contemporary music, DJs create new assemblages (Bennett 2001). Reynolds (1999, p. 274) notes that they do not uncritically recombine records though, because 'the best DJs are constructing a sort of argument about the historical roots of the music and where it should head in the future'. Rietveld (2011) further argues that creating this new mix, the third record, is also a curational practice, as the DJ selects records from the past that are worth remembering:

Through the creation of the third record in the DJ's mix, the recombination of (at least) two recordings, as well as a revision of disco's archival canon, house music may be perceived as a fluid musical archive, operating between the mediation of recorded musical production and lived cultural memory. (Rietveld 2011, p. 8)

At the 1990s parties, this third record develops in interaction with the shared memories of the crowds. Rietveld (2011) argues that these mixes can contain nostalgic references to old tracks as well as innovative reinterpretations of existing records. However, the number of songs a DJ can choose from at 1990s parties is limited, because they have to take audience expectations into account. 


\subsection{The audiences at $1990 \mathrm{~s}$ parties}

In my opinion, but that's how I see it, you're doing this for them. They buy a ticket because they expect you to give them a nice evening. Of course you can explore the boundaries, but we communicate this thing ... and if you aren't doing that, you're delivering a bad product so to speak. (Richard, 32, DJ/party organiser)

In this quote, a party organiser reflects on his responsibility to give the crowd the music they hope to hear. Familiarity and recognising things from the past are pivotal elements of the 1990s-themed parties. For the majority of the people I interviewed, recognising old tunes is essential if they are to derive pleasure from the events. This observation - that respondents particularly like the music they grew up with - is in line with a study of the consistency of musical preferences (Mulder et al. 2010). The authors report that particularly people who favour dance music are likely to listen to the same style of music when they get older. In general, they found that 'the majority of adolescents and young adults display high consistency in their preferences for music broadly divided into styles, and moderate to high consistency at the genre level' (Mulder et al. 2010, p. 79). Moreover, after asking 100 participants between the ages of 16 and 86 to rate excerpts of music, Holbrook and Schindler (1989) found that the subjects particularly liked the music that was popular during their late adolescence or early adulthood. In general, the people I interviewed have the same attachment to the music from this period of their lives, but the reasons given for enjoying these familiar songs are diverse, with the explanations ranging from new dance music being too slow to it being a poor derivative of hardcore or just too extreme. However, it should be noted that for many, the lighthearted decade-parties are an occasional nostalgic experience. From the interviews I conducted, it is apparent that the parties are part of a more varied repertoire of music consumption. Most respondents also go to concerts, club nights or dance events that are not focused on a specific decade. Certainly, nostalgia parties are one of the many experiences on offer by the cultural industries. The 1990s events are 'funny', a respondent casually remarked, and something you go to 'every now and then'. While some indulge in nostalgia at the 1990s themed-parties, they also emphasise the importance of openness to new genres. Nevertheless, the pleasure that audiences derive from these parties can only be understood by looking at how these representations of music history resonate with the cultural memories of ageing music consumers. In the next section of this article, I will further explore how the 1990s-themed events relate to the cultural biographies of the visitors of these events.

\subsection{Popular music and the life-course}

For older audiences, attending 1990s parties is a way of engaging with their own biographical experiences; they see the events as taking them back to a time when they had fewer responsibilities. Esther describes going to the parties as an 'eyeopener', making her realise that she now belongs to a generation that goes to these kinds of event. The parties make those in attendance aware of their former selves, particular periods in their lives and the ways in which their current identities are rooted in these pasts. Eric (39) explained to me that being a gabber is part of his personality, and he feels as if he is 'marked' by it. This is translated into him having a tattoo of party organiser and record label Thunderdome. Expressing a commitment to the legacy of this organisation in such a way is so common that people with a Thunderdome tattoo even get free entry to the company's parties through a separate entrance. Like the other gabbers, Eric emphasises the continuing significance of gabber music, both culturally and personally. These strong attachments to one particular genre are, however, more common with visitors of the early-parties. Nevertheless, the gabbers I interviewed were more likely to reveal their gabber identity at the actual parties than on a typical weekday. Eric's Thunderdome tattoo, for instance, is small and on his arm so that he does not get into trouble at work. Like the punks that Bennett (2006) studied, the gabbers are still committed to this style without necessarily expressing it visually. They feel that this is no longer appropriate now that they have children or a career.

The engagement with popular music revolves around life transitions such as relationships, having children or meeting new friends. These turning points marked transformations in the role of popular music in the everyday lives of my respondents. When people get older, they often still like the artists they used to listen 
in their youth, but the intensity of their fandom has diminished. Some of those I interviewed, especially the ones who go to the decade-parties, have left behind a time of major involvement with music as dedicated fans and are now more casual consumers. Nevertheless, they cherish the memories of these former periods as part of their personality. As Franca (24) explains: 'It was during my teens that I really loved the music of Di-rect, now I'm no longer able to become such a big fan of something. Well, I hope not, because it was quite extreme'. However, Franca insists that she will not throw away her scrapbooks and photos of this period, because of their personal relevance. As van Dijck (2004, p. 261) observes, we 'cherish our mediated memories as a formative part of our autobiographical and cultural identities'. Individuals are confronted with the task of reflexively finding a thread in their lives.

DeNora $(1999$, p. 45) convincingly demonstrated that music can be used as a tool to acquire such a coherent understanding of the self:

Equally significant is a form of 'introjection', a presentation of self to self, the ability to mobilize and hold on to a coherent image of 'who one knows one is'. And this involves the social and cultural activity of remembering, the composting of past experiences, for the cultivation of self-accountable imageries of self. Here music again comes to the fore, as part of the retinue of devices for memory retrieval (which is, of course, simultaneously memory construction).

In that sense, the 90s parties are mediating between former and current identities. In the next quote, a Dutch DJ describes an emotional reaction to one of his most popular songs. This shows how memories become part of narratives of the self and connect to highly personal experiences.

I was playing at a party in Switzerland ... I think it was in $2000 \ldots$ at the end of the set I played the hardcore version of Wonderful Days. During the song I saw a girl crying, standing against the barrier. This really touched me, so after the set I went to see her and asked what happened. She said that the first time she'd kissed her boyfriend this song was playing and he also proposed to her with the same song. (DJ, 43)

These personal memories point at a tension between personal and collective identities. Esther explains what she has in common with the other party-goers, even though their lives might have gone in different directions. On a cultural level, their biographies overlap, but when it comes to personal experiences they diverge:

I: What is it that you share?

I guess our music taste ... that's it ... and the time you grew up in, which is the same period. You've experienced similar things. I often see people who also went to parties back then. For some life turned out well, they are married with children and someone else is as desperate as before. (Esther, 31)

Tellingly, DeNora (1999, p. 45) describes integrating experiences to a personal narrative as a 'social and cultural activity'. Although the meanings of songs can be very personal, the memories they invoke are also a shared cultural heritage (van Dijck 2006).

With their appeal to shared memories, the parties function as a framework through which recollections of the decade are negotiated. In particular, the early parties play a pivotal role in preserving the musical legacy of the gabbers. The collective identity of the visitors of the early-parties is further enhanced by their clothes and way of dancing. The striking accentuation of the beat by quickly kicking the legs forward invokes typical gabber memories of the 1990s. Remarkably, a younger generation of gabbers maintains the appropriate style with completely shaven heads and the right tracksuits and trainers (Verhagen et al. 2000). Some of my respondents acquired the original 1990s tracksuits by buying them on auction sites. Moreover, using social media, meetings are organised at parties so that photos of large groups dressed in the old style can be taken. In this way, early-parties mediate between different generations. As noted above, the reflective nostalgia (Boym 2001) of the decade-parties does not entail such a rigid understanding of the musical past. The representations of the decade at these parties are instead humourous and exaggerated, and it is customary to wear some of the clothes that refer to fads and fashions of the past. Unlike the clothes of those at the early-parties, these garments are worn just for the occasion. In their playful approach to memory, these evenings resemble the 'I love the decade' series on television: 
Frothy and fast-moving, the I Love ... programmes featured an array of second-division comedians and minor celebrities quipping facetiously about the mass-cultural fads and follies of a particular decade: TV soap operas, hit movies, pop songs, hairstyles and fashions, toys and games, scandals, slogans and catchphrases. (Reynolds 2011, p. 27)

Similarly, the 1990s-themed parties are not about mere historical accuracy, but rather about the pleasure of sharing happy memories. Just like old friends do when they see each other again, the parties tend to idealise the past. However, this cultural style of surface and referentiality, which is equated with a loss of historicity by postmodern accounts of memory (Jameson 1985), does not imply that these parties are void of any serious personal meanings for audiences and lack a relationship to actual historical events. At the 1990s parties, fragments of the past that are usually just below the surface of our cultural identities temporarily take centre stage.

\section{Conclusion}

The aim of this study has been to explore how Dutch cultural industries feed into the attachment of music audiences to the popular music of the 1990s with parties dedicated to this decade. At these parties, local popular music heritages are presented to dance crowds. I also examined how audiences appropriate these memory products. The research to date has tended to conceptualise the 'marketing of memory' as sheer nostalgia that hampers creative innovation. However, little attention has been paid to the actual meanings of memory products to audiences beyond traditional understandings of nostalgia as cultural longing or amnesia (Grainge 2000, Pickering and Keightley 2006). This study has drawn, therefore, upon theories that conceptualise the consumption of heritage as a performance, involving active processes of remembering (Bagnall 2003).

To highlight the different ways in which musical memories are invoked at dance events, I made an idealtypical distinction between decade-parties and early-parties. This corroborates the claim of Pickering and Keightley (2006) that nostalgia has multiple manifestations and encompasses various forms of engagement with the past. While the 'reflective nostalgia' of the decade-parties playfully refers to the passing of popular styles, songs and fashions, the 'restorative nostalgia' (Boym 2001) of the early-parties aims to excavate original house sounds. The diverse mix of music at the decade-parties is reflected by the stylistic heterogeneity (Muggleton 2000) of their attendees. What makes these events attractive to audiences are their familiarity and the sensory experience of reminiscing. Since this ensures a steady flow of visitors, the format of the decade-parties is frequently employed by clubs. I found that the visitors and organisers of the early-parties have a stronger sense of collective identity and are more committed to the heritage of specific genres. These parties are thus a framework through which particular cultural identities are constructed and maintained.

On a personal level, the nostalgia of these events allows people to engage with the ways in which their present identities are rooted in the past. Moreover, the parties mediate between different generations. At these events, younger audiences are familiarised with the musical heritage of the 1990s. In relation to this, I highlighted the role of the DJs curating the evenings by remixing archival material to produce cultural memories or 'new musical forms based on reinterpretations of recorded memory' (Rietveld 2011, p. 17). By recombining existing recordings, the 'DJarchivist' creates a fluid musical narrative (Rietveld 2011) of the 1990s with which the dance crowds can identify. This shows that the nostalgia of these parties not only looks back in a regressive fashion, but also is also capable of offering fresh perspectives on the musical heritage of this decade.

This study is, of course, focused on a very specific phenomenon. In future studies, the differences between generations in terms of their engagement with musical pasts could be further explored for other genres and musical settings. The current study found that nostalgia is a pertinent concept in such endeavours, particularly because cultural industries also employ the term for media networks, like nostalgia radio to target baby boomers.5 As this concept has wide currency outside academia, it is likely to be a very useful 
term when it comes to further exploring the meanings of popular music histories in the everyday lives of music audiences.

\section{Acknowledgements}

This research has been supported as part of the Popular Music Heritage, Cultural Memory and Cultural Identity (POPID) project by the HERA Joint Research Programme (www.heranet.info) which is co-funded by AHRC, AKA, DASTI, ETF, FNR, FWF, HAZU,IRCHSS, MHEST, NWO, RANNIS, RCN, VR and The European Community FP7 2007-2013, under 'the Socio-economic Sciences and Humanities programme'. The author would like to thank Hillegonda Rietveld, Les Roberts, Vaughn Schmutz and the two anonymous reviewers for their valuable comments and suggestions.

\section{Notes}

1. All Dutch quotes have been translated by the author.

2. To my knowledge, these parties are also organised in Australia, the UK and Belgium.

3. For a more comprehensive overview of the youth culture of the gabbers, see Verhagen et al. (2000) and Reynolds (1999).

4. Needless to say, the artistic legacy of gabberhouse is also audible at parties with more recent genres like hardstyle. However, in this article, I focus on parties that explicitly engage with music from the 1990s.

5. In the Netherlands, Radio 5 Nostalgia (www.radio5nostalgia.nl/) and an online 'Nostalgia shop' (www.dewinkelvandenostalgie.nl/) both target baby boomers.

\section{References}

Atkinson, D., 2008. The heritage of mundane places. In: B. Graham and P. Howard, eds. The Ashgate research companion to heritage and identity. Aldershot: Ashgate, 381-395.

Baer, A., 2001. Consuming history and memory through mass media products. European Journal of Cultural Studies, $4(4), 491-501$.

Bagnall, G., 2003. Performance and performativity at heritage sites. Museum and Society, 1(2), 87-103.

Bennett, A., 1999. Subcultures or neo-tribes? Rethinking the relationship between youth, style and musical taste. Sociology, 33 (3), 599-617.

Bennett, A., 2001. Cultures of popular music. Buckingham: Open University Press.

Bennett, A., 2006. Punk's not dead: the continuing significance of punk rock for an older generation of fans. Sociology, 40 (2), 219.

Bennett, A., 2008. 'Things they do look awful cool': ageing rock icons and contemporary youth audiences. Leisure/Loisir, 32 (2), 259-278.

Bennett, A., 2009. 'Heritage rock': rock music, representation and heritage discourse. Poetics, 37, 474-489.

Bevers, T., 2005. Cultural education and the canon: a comparative analysis of the content of secondary school exams for music and art in England, France, Germany, and the Netherlands, 1990-2004. Poetics, 33, 388-416.

Boym, S., 2001. The future of nostalgia. New York, NY: Basic Books.

Burgoyne, R., 2003. From contested to consensual memory: the rock and roll hall of fame museum. In: K. Hodgkin and S. Radstone, eds. Contested pasts: the politics of memory. London: Routledge, 208-220.

Corbin, J.M. and Strauss, A., 1990. Grounded theory research: procedures, canons, and evaluative criteria. Qualitative Sociology, 13 (1), 3-21.

Davis, F., 1979. Yearning for yesterday: a sociology of nostalgia. New york, NY: Free Press.

DeNora, T., 1999. Music as a technology of the self. Poetics, 27 (1), 31-56.

Graham, B. and Howard, P., 2008. Heritage and identity. In: B. Graham and P. Howard, eds. The Ashgate research companion to heritage and identity. Aldershot: Ashgate, 1-15.

Grainge, P., 2000. Nostalgia and style in retro America: moods, modes, and media recycling. Journal of American \& Comparative Cultures, 23 (1), 27-34.

Harvey, D.C., 2008. The history of heritage. In: B. Graham and P. Howard, eds. The Ashgate research companion to heritage and identity. Aldershot: Ashgate, 19-36.

Hayes, D., 2006. 'Take those old records off the shelf': youth and music consumption in the postmodern age. Popular Music and Society, 29 (1), 51-68.

Hesmondhalgh, D., 2005. Subcultures, scenes or tribes? None of the above. Journal of Youth Studies, 8 (1), 21-40.

Hitters, E. and van de Kamp, M., 2010. Tune in, fade out: music companies and the classification of domestic music products in the Netherlands. Poetics, 38 (5), 461-480.

Holbrook, M.B. and Schindler, R.M., 1989. Some exploratory findings on the development of musical tastes. The Journal of Consumer Research, 16 (1), 119-124.

Hoskins, A., 2001. New memory: mediating history. Historical Journal of Film Radio and Television, 21 (4), 333346.

Jameson, F., 1985. Postmodernism and consumer society. In: H. Foster, ed. Postmodern culture. London: Pluto Press, $111-125$. 
Jameson, F., 1991. Postmodernism, or, the cultural logic of late capitalism. Durham, NC: Duke University Press Books.

Janata, P., Tomic, S.T., and Rakowski, S.K., 2007. Characterisation of music-evoked autobiographical memories. Memory, 15 (8), 845-860.

Kong, L., 1999. The invention of heritage: popular music in Singapore. Asian Studies Review, 23 (1), 1-25.

Kotarba, J.A., 2002. Rock 'n' roll music as a timepiece. Symbolic Interaction, 25 (3), 397-404.

Lowenthal, D., 1989. Nostalgia tells it like it wasn't. In: C. Shaw and M. Chase, eds. The imagined past: history and nostalgia. Manchester: Manchester University Press, 18-32.

McLeod, K., 2001. Genres, subgenres, sub-subgenres and more: musical and social differentiation within electronic/dance music communities. Journal of Popular Music Studies, 13(1), 59-75.

Muggleton, D., 2000. Inside subculture: the postmodern meaning of style. Oxford: Berg.

Mulder, J., et al., 2010. From death metal to R\&B? Consistency of music preferences among Dutch adolescents and young adults. Psychology of Music, 38 (1), 67-83.

Pickering, M. and Keightley, E., 2006. The modalities of nostalgia. Current Sociology, 54(6), 919-940.

Reynolds, S., 1999. Generation ecstasy: into the world of techno and rave culture. New York, NY: Routledge.

Reynolds, S., 2011. Retromania: pop culture's addiction to its own past. London: Faber and Faber.

Rietveld, H.C., 2011. Disco's revenge: house music's nomadic memory. Dancecult: Journal of Electronic Dance Music Culture, 2 (1), 4-23.

Schmutz, V., 2005. Retrospective cultural consecration in popular music. American Behavioral Scientist, 48 (11), 1510.

Sedikides, C., et al., 2008. Nostalgia as enabler of self-continuity. In: F. Sani, ed. Self-continuity: individual and collective perspectives. New York, NY: Psychology Press, 227-239.

Smith, L., 2006. Uses of heritage. London: Routledge.

Thornton, S., 1995. Club cultures: music, media and subcultural capital. Cambridge: Polity Press.

van Dijck, J., 2004. Mediated memories: personal cultural memory as object of cultural analysis. Continuum, 18 (2), 261-277.

van Dijck, J., 2006. Record and hold: popular music between personal and collective memory. Critical Studies in Media Communication, 23 (5), 357-374.

Verhagen, S., et al., 2000. Fast on 200 beats per minute. Youth \& Society, 32 (2), 147-164.

Wertsch, J.V., 2002. Voices of collective remembering. Cambridge: Cambridge University Press.

Wu, E.M., 2010. Memory and nostalgia in youth music cultures: finding the vibe in the San Francisco bay area rave scene, 2002-2004. Dancecult: Journal of Electronic Dance Music Culture [Online], 1 (2). Available from: http://dj.dancecult.net/index.php/journalarticle/viewArticle/41 [Accessed 23 May 2012]. 